\title{
Effect of aortic aneurysm replacement on outcomes after bicuspid aortic valve surgery: Validation of contemporary guidelines
}

\author{
Daniel Rinewalt, MD, ${ }^{\text {a }}$ Patrick M. McCarthy, MD, ${ }^{\text {a }}$ Sukit Chris Malaisrie, MD, ${ }^{a}$ Paul W. M. Fedak, MD, PhD, ${ }^{b}$ \\ Adin-Cristian Andrei, PhD, ${ }^{\mathrm{a}}$ Jyothy J. Puthumana, $\mathrm{MD},{ }^{\mathrm{c}}$ and Robert O. Bonow, $\mathrm{MD}^{\mathrm{c}}$
}

\begin{abstract}
Objective: Bicuspid aortic valve (BAV) disease is associated with aortic dilatation and aneurysm (AN) formation. The American College of Cardiology/American Heart Association (ACC/AHA) 2006 guidelines recommend replacement of the ascending aorta for an aortic diameter (AD) $>45 \mathrm{~mm}$ in patients undergoing aortic valve replacement (AVR). We evaluated the outcomes of AVR and AVR with aortic replacement (AVR/AN).
\end{abstract}

\begin{abstract}
Methods: We retrospectively reviewed (2004-2011) the data from 456 patients with BAV and compared the morbidity and mortality between the AVR and AVR/AN groups and 3 subgroups: AVR with an AD $<45$ $\mathrm{mm}$; AVR/AN with an AD of 45 to $49 \mathrm{~mm}$; and AVR/AN with an AD of $\geq 50 \mathrm{~mm}$. Propensity score matching was used to reduce bias.
\end{abstract}

Results: Of the 456 patients, 250 (55\%) underwent AVR and 206 (45\%) AVR/AN, with 98\% compliance with the current guidelines. The overall 30-day mortality was $0.9 \%$. The AVR AD $<45$-mm group had adjusted short- and medium-term survival similar to that of the AVR/AN AD 45- to 49-mm and AVR/AN AD $\geq 50$-mm groups, with a 30-day mortality of $0.8 \%, 0 \%$, and $1.9 \%$, respectively $(P=.41)$. The propensity score-matched AVR/AN AD $\geq 50$-mm group had significantly greater rates of reintubation than either the AVR AD $<45-\mathrm{mm}(P=.012)$ or AVR/AN AD 45- to 49-mm $(P=.04)$ group and greater rates of prolonged ventilation $(P=.022)$ than the AVR AD $<45$-mm group. No significant differences were found in reoperation or myocardial infarction among the subgroups.

Conclusions: In patients with undergoing AVR, no increase was seen in morbidity or mortality when adding aortic replacement with an AD of 45 to $49 \mathrm{~mm}$, in accordance with the 2006 ACC/AHA guidelines, although the $\mathrm{AVR} / \mathrm{AN} \mathrm{AD} \geq 50$-mm group had a greater risk of respiratory complications. Our findings indicate that compliance with the ACC/AHA guidelines is safe in select centers. (J Thorac Cardiovasc Surg 2014;148:2060-9)

See related commentary on pages $2070-1$.

Bicuspid aortic valve (BAV) disease is the most common congenital heart lesion and occurs in $1 \%$ to $2 \%$ of the

From the Divisions of Cardiac Surgery ${ }^{\mathrm{a}}$ and Cardiology, ${ }^{\mathrm{c}}$ Martha and Richard Melman Family Bicuspid Aortic Valve Program, Bluhm Cardiovascular Institute, Department of Surgery, Northwestern Memorial Hospital, Northwestern University Feinberg School of Medicine, Chicago, Ill; and Department of Cardiac Scien-

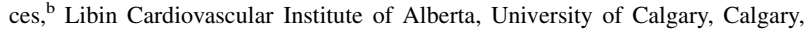
Alberta, Canada

The present study was supported by the Bluhm Cardiovascular Institute and the Martha and Richard Melman Family Bicuspid Aortic Valve Program, Bluhm Cardiovascular Institute, Northwestern Memorial Hospital.

Disclosures: Dr McCarthy has been a consultant to, received royalties from, and has intellectual property with, Edwards Lifesciences, and Dr Malaisrie has been a consultant to Edwards Lifesciences. All other authors have nothing to disclose with regard to commercial support.

Received for publication Oct 11, 2013; revisions received Feb 27, 2014; accepted for publication March 17, 2014; available ahead of print April 19, 2014.

Address for reprints: Patrick M. McCarthy, MD, Division of Cardiac Surgery, Bluhm Cardiovascular Institute, Department of Surgery, Bluhm Cardiovascular Institute, Northwestern Memorial Hospital, Northwestern University Feinberg School of Medicine, 201 East Huron St, Suite 11-140, Chicago, IL 60611-2908 (E-mail: pmccart@nmh.org).

$0022-5223 / \$ 36.00$

Copyright (c) 2014 by The American Association for Thoracic Surgery

http://dx.doi.org/10.1016/j.jtcvs.2014.03.027 population. ${ }^{1,2}$ Although the exact mechanism is not yet fully understood, BAV is a significant risk factor for aortic dilatation, aneurysm (AN) development, and acute dissection. $^{2}$ Recent evidence has indicated dilatation of the ascending aorta occurs secondary to degeneration of the aortic media, similar to other connective tissue disorders, primarily owing to apoptosis of neural crest derivatives. ${ }^{2}$ Regardless of the causative mechanism, the lifetime risk of aortic dissection in patients with BAV has been reported to be approximately 5 to 9 times greater than that of the general population..$^{2-5}$ The guidelines for the management of valvular heart disease issued by the American College of Cardiology and American Heart Association (ACC/AHA) task force in 2006 have recommended replacement of the ascending aorta in patients with BAV in whom the aortic diameter (AD) is $>50 \mathrm{~mm} .^{6}$ Additionally, for patients with BAV who meet the criteria for aortic valve replacement (AVR), the guidelines have recommended replacement of the ascending aorta at valve replacement (AVR/AN) for aortic dilatation $>45 \mathrm{~mm}$. ${ }^{6}$ These specific recommendations, based on expert consensus and retrospective observational series, were a new addition to the $2006 \mathrm{ACC} / \mathrm{AHA}$ guidelines compared with the 1998 version for valvular heart disease and have not been formally evaluated in a large contemporary series of patients.? 


\author{
Abbreviations and Acronyms \\ ACC $=$ American College of Cardiology \\ $\mathrm{AD}=$ aortic diameter \\ AHA $=$ American Heart Association \\ $\mathrm{AN}=$ aneurysm \\ AVR $=$ aortic valve replacement \\ $\mathrm{BAV}=$ bicuspid aortic valve \\ $\mathrm{CAD}=$ coronary artery disease \\ $\mathrm{CI}=$ confidence interval \\ $\mathrm{CT}=$ computed tomography \\ $\mathrm{HR}=$ hazard ratio \\ MRI = magnetic resonance imaging \\ PS = propensity score
}

The present study was designed to address our overall compliance with the 2006 ACC/AHA guidelines in patients with BAV undergoing AVR and to determine whether the addition of aortic replacement in patients with an $\mathrm{AD}$ of 45 to $49 \mathrm{~mm}$ would be associated with increased perioperative and medium-term morbidity and mortality.

\section{METHODS \\ Patient Population}

Data for the present project were obtained from the Cardiovascular Research Database in the Clinical Trial Unit of the Bluhm Cardiovascular Institute at Northwestern Memorial Hospital. The institutional review board at Northwestern University approved the use of this database (project no. STU00012288). Any subjects refusing participation in the project were not included in the analysis. The Cardiovascular Research Database was queried for patients with BAV who had undergone aortic valve surgery from April 2004 to March 2011, and a total of 470 patients was found. After excluding patients with preoperative aortic dissection $(n=4)$, ventricular assist device or transcatheter aortic valve implantation $(\mathrm{n}=5)$, and missing aortic measurements $(\mathrm{n}=5)$, we arrived at a final cohort of 456 patients. Preoperative computed tomography (CT) or magnetic resonance imaging (MRI) was performed in 417 patients $(91.4 \%)$ to assess aortic dilatation, which was the current practice in our center for patients with a suspicion of BAV before surgery. Echocardiographic data were used when CT or MRI information was not available. Coronary artery disease (CAD) information was available for 447 patients. Of them, $115(26 \%)$ had CAD. For 9 patients (age, $33.6 \pm$ 8.9 years; 3 emergency cases) no CAD data were available. Pulmonary hypertension (pulmonary artery systolic pressure $>35 \mathrm{~mm} \mathrm{Hg}$ ) was present in $108(30 \%)$ of the 363 patients with information available. Aortic stenosis and aortic insufficiency $\geq 2+$ was present in $70 \%$ and $48 \%$, respectively (Table 1$)$.

\section{Outcome Measurements}

The short-term outcomes included length of intensive care unit stay, perioperative complications, and operative, in-hospital, and 30-day mortality according to The Society of Thoracic Surgeons database definitions. Survival after discharge was determined from the Social Security Death Index and chart review, in addition to annual mailed questionnaires and telephone surveys obtained as part of a routine protocol for the Cardiovascular Research Database registry. To evaluate the effect of the AD cutoff points suggested by the 2006 ACC/AHA guidelines, we identified 3 subgroups of interest: (1) AVR with an $\mathrm{AD}<45 \mathrm{~mm}$, (2) AVR/AN with an AD of 45 to
$49 \mathrm{~mm}$, and (3) AVR/AN with an AD of $\geq 50 \mathrm{~mm}$. Pairwise comparisons of these 3 subgroups were performed as follows:

1. AVR AD $<45 \mathrm{~mm}$ compared with AVR/AN AD of 45 to $49 \mathrm{~mm}$ : these cohorts were closest to the ACC/AHA recommended cutoff values and, hence, were likely to provide the most practical validation of the guidelines. If worse outcomes occurred with the addition of ascending aortic replacement surgery, it would be most likely to be observed in this AVR/ AN cohort

2. $\mathrm{AVR} \mathrm{AD}<45 \mathrm{~mm}$ compared with $\mathrm{AVR} / \mathrm{AN} \mathrm{AD}$ of $\geq 50 \mathrm{~mm}$

3. AVR/AN AD of 45 to $49 \mathrm{~mm}$ compared with AVR/AN AD of $\geq 50 \mathrm{~mm}$

\section{Statistical Analysis}

To reduce potential confounding owing to baseline imbalances, propensity score (PS) matching methods were used. ${ }^{8}$ The patient groups compared were PS-matched 1-to-1 using a greedy algorithm with a caliper size of 0.05 logit PS standard deviation units. Balance in the baseline characteristics in the PS-matched groups was assessed using formal statistical testing and confirmed by way of kernel-smoothed PS histogram similarity (Figure 1). The matching factors included age, gender, body surface area, preoperative creatinine level, preoperative left ventricular ejection fraction, Ambler score, angina, $\mathrm{CAD}$, family history of $\mathrm{CAD}$, diabetes, hypercholesterolemia, hypertension, cerebrovascular accident, previous coronary artery bypass grafting, previous valve surgery, previous heart failure, New York Heart Association functional class III-IV, history of atrial fibrillation, preoperative medication (eg, $\beta$-blockers, angiotensinconverting enzyme inhibitors, lipid-lowering, calcium channel antagonists), aortic insufficiency $\geq 2$, aortic stenosis, elective status, and surgeon

Postoperative overall survival was summarized using Kaplan-Meier curves, and group comparisons were based on the log-rank test. Mediumterm mortality comparisons in PS-matched groups also included age-, gender-, and surgeon-adjusted PS pair-stratified Cox regression model with robust covariance matrix. ${ }^{9}$ Hazard ratios (HRs) and corresponding $95 \%$ confidence intervals (CIs) were determined. The appropriateness of the proportional hazards assumption was assessed visually. The baseline demographics and preoperative characteristics are summarized in Table 1, and the operative details and outcomes are listed in Table 2. The outcomes between the subgroups of interest using PS matching are listed in Table 3. One-way analysis of variance or Kruskal-Wallis test was used to compare the continuously distributed variables. The chi-square test or Fisher's exact test was used to compare the discrete variables. Medium-term survivorship in the PS-matched analyses is displayed in Figure 2. Throughout, a 2-sided $5 \%$ statistical significance level was used, without multiplicity adjustments. All statistical analyses were performed using Statistical Analysis Systems, version 9.3, software (SAS Institute, Inc, Cary, NC).

\section{RESULTS}

In the entire cohort of 456 patients with BAV, the overall 30-day mortality (Table 2$)$ was $0.9 \%(n=4)$. Perioperative events included 3 strokes $(0.7 \%), 1$ perioperative myocardial infarction $(0.2 \%)$, and 30 reoperations for bleeding $(6.6 \%$; Table 2$)$. The average patient follow-up was $4.7 \pm$ 2.1 years, and the incidence of perioperative or later aortic dissection was $0 \%$. Of the 456 patients with BAV, 250 $(55 \%)$ were in the AVR group and $206(45 \%)$ in the AVR/AN group, for a 98\% compliance rate with the 2006 ACC/AHA recommendations for aortic replacement in those with an $\mathrm{AD}$ of $\geq 45 \mathrm{~mm}$. No significant differences were found in the short- or medium-term outcomes between the AVR and AVR/AN groups regarding any complications $(34 \%$ vs $37 \%, P=.6)$ or 30 -day mortality $(0.8 \%$ vs $1 \%$, 
TABLE 1. Baseline characteristics of entire cohort (all BAV patients) and 3 patient subgroups

\begin{tabular}{|c|c|c|c|c|c|}
\hline \multirow[b]{2}{*}{ Variable } & \multirow[b]{2}{*}{$\begin{array}{l}\text { Entire cohort } \\
\quad(n=456)\end{array}$} & \multicolumn{4}{|c|}{ Subgroups } \\
\hline & & $\begin{array}{c}\text { AVR AD }<45 \mathrm{~mm} \\
(\mathrm{n}=\mathbf{2 4 5})\end{array}$ & $\begin{array}{c}\text { AVR/AN AD 45-49 mm } \\
(n=70)\end{array}$ & $\begin{array}{c}\text { AVR/AN AD } \geq 50 \mathrm{~mm} \\
(\mathrm{n}=\mathbf{1 0 3})\end{array}$ & $P$ value \\
\hline Age (y) & $57.8 \pm 13.3$ & $61.1 \pm 13.2$ & $53.8 \pm 12.8$ & $54.0 \pm 11.5$ & $<.001$ \\
\hline Weight (kg) & $84.6 \pm 18.2$ & $82.7 \pm 17.9$ & $86.1 \pm 18.8$ & $88.7 \pm 18.7$ & .016 \\
\hline Body surface area $\left(\mathrm{m}^{2}\right)$ & $2.0 \pm 0.3$ & $2.0 \pm 0.3$ & $2.0 \pm 0.2$ & $2.1 \pm 0.3$ & .003 \\
\hline Aortic stenosis only & $120(26)$ & $79(32)$ & $13(19)$ & $19(18)$ & .007 \\
\hline Aortic insufficiency $\geq 2$ only & $121(27)$ & $42(17)$ & $27(39)$ & $36(35)$ & $<.001$ \\
\hline Aortic stenosis and insufficiency & $202(44)$ & $124(40)$ & $28(40)$ & $39(38)$ & .05 \\
\hline No aortic stenosis or insufficiency & $12(3)$ & $0(0)$ & $2(3)$ & $9(9)$ & $<.001$ \\
\hline Ejection fraction $(\%)$ & & & & & .48 \\
\hline Median & 60.0 & 60.0 & 60.0 & 60.0 & \\
\hline Q1, Q3 & $53.0,65.0$ & $50.0,65.0$ & $55.0,65.0$ & $55.0,63.0$ & \\
\hline Cross-section aortic ratio* $\left(\mathrm{cm}^{2} / \mathrm{m}\right)$ & & & & & $<.001$ \\
\hline Median & 8.0 & 6.2 & 9.8 & 12.4 & \\
\hline Q1, Q3 & $6.0,10.6$ & $5.0,7.4$ & $9.2,10.4$ & $11.4,13.7$ & \\
\hline Female gender & $110(24)$ & $71(29)$ & $11(16)$ & $19(18)$ & .022 \\
\hline Current smoker & $20(4)$ & $12(5)$ & $2(3)$ & $3(3)$ & .59 \\
\hline Diabetes & $47(10)$ & $35(14)$ & $6(9)$ & $5(5)$ & .029 \\
\hline Dyslipidemia & $242(53)$ & $149(61)$ & $31(44)$ & $43(42)$ & .001 \\
\hline Renal failure & $8(2)$ & $7(3)$ & $0(0)$ & $1(1)$ & .22 \\
\hline Hypertension & $238(52)$ & $136(56)$ & $40(57)$ & $49(48)$ & .33 \\
\hline Chronic lung disease & $38(8)$ & $24(10)$ & $5(7)$ & $7(7)$ & .59 \\
\hline Peripheral vascular disease & $9(2)$ & $7(3)$ & $1(1)$ & $1(1)$ & .49 \\
\hline Cerebrovascular disease & $31(7)$ & $20(8)$ & $5(7)$ & $4(4)$ & .36 \\
\hline Previous stroke & $15(3)$ & $8(3)$ & $3(4)$ & $2(2)$ & .66 \\
\hline Previous CABG & $13(3)$ & $10(4)$ & $1(1)$ & $1(1)$ & .21 \\
\hline Previous valve procedure & $30(7)$ & $12(5)$ & $6(9)$ & $8(8)$ & .40 \\
\hline Previous other cardiac surgery & $12(3)$ & $9(4)$ & $0(0)$ & $3(3)$ & .27 \\
\hline Previous PCI & $23(5)$ & $17(7)$ & $1(1)$ & $3(3)$ & .09 \\
\hline Previous MI & $19(4)$ & $14(6)$ & $1(1)$ & $2(2)$ & .13 \\
\hline $\mathrm{CHF}$ & $94(21)$ & $65(27)$ & $12(17)$ & $9(9)$ & $<.001$ \\
\hline NYHA class III-IV & $109(24)$ & $76(31)$ & $13(19)$ & $12(12)$ & $<.001$ \\
\hline AF history & $61(13)$ & $35(14)$ & $2(3)$ & $18(17)$ & .015 \\
\hline Angina & $57(13)$ & $38(16)$ & $8(11)$ & $7(7)$ & .08 \\
\hline
\end{tabular}

Data presented as n (\%), unless otherwise noted. $B A V$, Bicuspid aortic valve; $A V R$, aortic valve replacement; $A D$, aortic diameter; $A N$, aneurysm; $A V R / A N$, AVR with ascending aortic replacement; $Q$, quartile; $C A B G$, coronary artery bypass grafting; $P C I$, percutaneous coronary intervention; $M I$, myocardial infarction; $C H F$, congestive heart failure; NYHA, New York Heart Association; $A F$, atrial fibrillation. *Calculated as the aortic cross-sectional area (in square centimeters) divided by the patient's height (in meters).

$P=.9)$. The midterm survival-adjusted HR (AVR reference) was $0.83(95 \% \mathrm{CI}, 0.34-2.03 ; P=.7)$. Of 44 reoperations, the 30-day mortality was $0 \%$ for AVR only $(\mathrm{n}=23)$ and for AVR/AN $(\mathrm{n}=21)$. We were unable to ascertain the cause of death for the late deaths, because all occurred outside our institution. Two AVR patients required reoperation: one for structural valve degeneration after 7 years and one for endocarditis after 2 years. No reoperations occurred in the AVR/AN group.

In the entire cohort $(\mathrm{n}=456), 5$ patients had an $\mathrm{AD}$ of $\geq 45 \mathrm{~mm}(45 \mathrm{~mm}, \mathrm{n}=1 ; 46 \mathrm{~mm}, \mathrm{n}=3$; and $47 \mathrm{~mm}$, $\mathrm{n}=1$ ) but did not undergo aortic replacement surgery. The treatment of these 5 patients was not in compliance with the 2006 guidelines; thus, for the total AVR cohort of 250 , this yielded a $98 \%$ compliance rate. Of these 5,1 patient underwent AVR before the 2006 ACC/AHA guidelines were published, and 2 underwent aortoplasty. In addition, 33 patients underwent AVR/AN with an $\mathrm{AD}<45 \mathrm{~mm}$. All 103 patients with an AD of $\geq 50 \mathrm{~mm}$ underwent AVR (100\% compliance with the 2006 ACC/AHA guidelines). The data from these 38 (5 plus 33 ) patients were not included in Tables 1 and 2; our tabulated analysis of the subgroups: (1) AVR with an AD $<45 \mathrm{~mm}(\mathrm{n}=245)$; (2) AVR/AN with an AD of 45 to $49 \mathrm{~mm}(\mathrm{n}=70)$; and (3) AVR/AN with an $\mathrm{AD}$ of $\geq 50 \mathrm{~mm}(\mathrm{n}=103)$.

Within the AVR AD <45-mm group, 235 (96\%) had received a bioprosthetic valve (Table 2). In the AVR/AN $\mathrm{AD} 45$ - to 49-mm and AVR/AN AD $\geq 50$-mm groups (70 plus $103, \mathrm{n}=173), 139$ patients $(80 \%)$ underwent aortic root replacement with a valve conduit (Bentall procedure; 
PS-Matched Analysis 1: AVR AD $<45 \mathrm{~mm}$ and AVR/AN AD 45-49mm

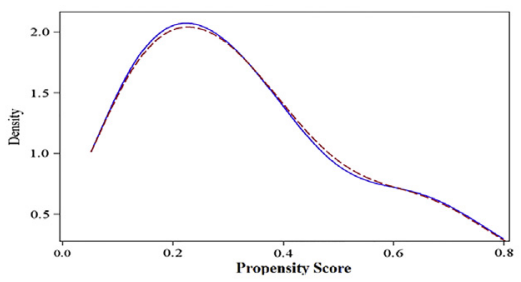

PS-Matched Analysis 2: AVR AD $<45 \mathrm{~mm}$ and AVR/AN AD $\geq 50 \mathrm{~mm}$

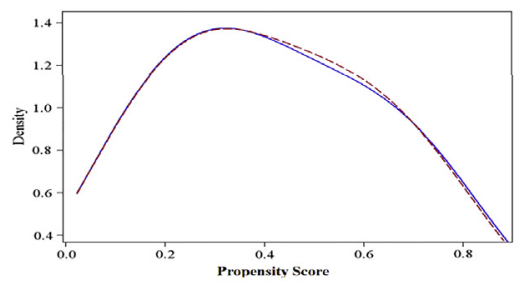

PS-Matched Analysis 3: AVR/AN AD 45-49mm and AVR/AN AD $\geq 50 \mathrm{~mm}$

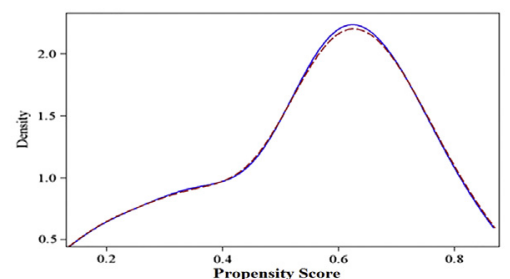

FIGURE 1. Assessment of the overall balance in baseline covariates in the 3 propensity score $(P S)$-matched analyses. Similarity in kernel-smoothed PS histograms depicted indicated adequate balance between the groups compared. AVR, Aortic valve replacement; $A D$, aortic diameter; $A N$, aneurysm.

Table 2). Most of these were stented bovine pericardial valves sewn into a Dacron graft. Of the remaining AVR/AN patients, $20(11.6 \%)$ underwent AVR with a separate aortic graft and $13(7.5 \%)$ underwent valve-sparing aortic root replacement (Table 2).

Other preoperative, intraoperative, and postoperative characteristics of the entire cohort and the 3 subgroups are summarized in Tables 1 and 2. Results from the 3 PSmatched pairwise comparisons (AVR AD $<45 \mathrm{~mm}$, $\mathrm{n}=245$; AVR/AN AD 45 to $49 \mathrm{~mm}, \mathrm{n}=70$; and AVR/ $\mathrm{AN} A D \geq 50 \mathrm{~mm}, \mathrm{n}=103$ ) are listed in Table 3 .

\section{Analysis 1: AVR With AD $<45$ mm Compared With AVR/AN With AD 45 to 49 mm}

In the original groups (245 AVR and 70 AVR/AN AD 45to 49 -mm patients), no significant differences were found in overall survival (adjusted HR, 0.24; 95\% CI, 0.05-1.12; $P=.07$, AVR reference group). After PS matching, 47 pairs were created, and the 30-day mortality was $0 \%$ in both groups (Table 3). As displayed in Figure 1, the kernelsmoothed histograms of the PS values were virtually identical, indicating an excellent overall baseline covariate balance. The aortic crossclamp time, cardiopulmonary bypass time, and the use of circulatory arrest were greater in the AVR/AN group $(P<.001$; Table 3$)$. No differences were found in morbidity. The medium-term overall survival was not significantly different (adjusted HR, $1.25 ; 95 \% \mathrm{CI}$, $0.16-9.87 ; P=.83$ ), with a 5 -year survival of $94.0 \%$ in the AVR cohort and $95.7 \%$ in the AVR/AN group (Figure 2).

\section{Analysis 2: AVR With AD $<45$ mm Compared With AVR/AN With $A D \geq 50$ mm}

We found no significant differences in the medium-term overall survival between the 245 AVR patients (reference group) and $103 \mathrm{AVR} / \mathrm{AN} \mathrm{AD} \geq 50$-mm patients (adjusted HR, 1.0; 95\% CI, 0.36-2.8; $P=1.0$ ). After PS matching, 62 pairs were created. Adequate baseline covariate balance was achieved, reflected by the PS distribution similarity shown in Figure 1. No significant difference was found in 30 -day mortality $(0 \%$ in AVR vs $3.2 \%$ in AVR/AN, $P=.15$; Table 3 ). The AVR/AN patients had significantly longer perfusion and crossclamp times, a greater use of circulatory arrest $(P<.001)$, and a significantly greater risk of prolonged ventilation $(8 \%$ vs $0 \%, P=.022)$ and reintubation ( $10 \%$ vs $0 \%, P=.012$; Table 3$)$. No other significant differences were found in morbidity or all-cause mortality (adjusted HR, 1.59; 95\% CI, 0.52-4.87; $P=.42$ ), with 5-year survival at $89.9 \%$ in the AVR and $88.1 \%$ in the AVR/AN group (Figure 2).

\section{Analysis 3: AVR/AN With AD 45 to 49 mm Compared With AVR/AN With AD $\geq \mathbf{5 0} \mathbf{~ m m}$}

In the original groups, 70 patients were in the AVR/AN AD 45- to 49-mm and 103 were in the AVR/AN AD $\geq$ 50-mm group. No significant differences in overall survival were found (adjusted HR, 3.03; 95\% CI, 0.61-15.02; $P=.2 ;$ AVR/AN AD 45- to 49-mm reference group). A total of 36 PS-matched pairs were obtained. The data shown in Figure 1 indicate adequate baseline covariate balance between groups. No significant difference was found in 30-day mortality $(0 \%$ in the AVR/AN AD 45 - to $49-\mathrm{mm}$ group and $2.8 \%$ in the AVR/AN AD $\geq 50-\mathrm{mm}$ group; $P=.31$; Table 3 ). The cardiopulmonary bypass duration and crossclamp time were longer in the AVR/AN AD $\geq$ 50 -mm cohort $(P=.05)$, and the use of circulatory arrest was greater $(P<.001$; Table 3$)$. Reintubation was greater in the AVR/AN $\mathrm{AD} \geq 50-\mathrm{mm}$ group $(11 \%$ vs $0 \%$, $P=.040$; Table 3 ). Medium-term survival was not significantly different (adjusted HR, 2.35; 95\% CI, 0.12-45.94; $P=.57$ ), with a 5-year survival rate at $97.2 \%$ among patients with smaller aneurysms and $90.2 \%$ among those with larger aneurysms (Figure 2).

\section{DISCUSSION}

In the present study, our primary finding was that the addition of aortic aneurysm replacement in patients with 
TABLE 2. Intraoperative, postoperative characteristics of the entire cohort (all with BAV) and 3 subgroups

\begin{tabular}{|c|c|c|c|c|c|}
\hline \multirow[b]{2}{*}{ Variable } & \multirow[b]{2}{*}{$\begin{array}{c}\text { Entire cohort } \\
(n=456)\end{array}$} & \multicolumn{4}{|c|}{ Subgroups } \\
\hline & & $\begin{array}{c}\text { AVR AD }<45 \text { mm } \\
(n=245)\end{array}$ & $\begin{array}{c}\text { AVR/AN } \\
\text { AD } 45-49 \mathrm{~mm}(\mathrm{n}=70)\end{array}$ & $\begin{array}{c}\text { AVR/AN AD } \geq 50 \mathrm{~mm} \\
(\mathbf{n}=\mathbf{1 0 3})\end{array}$ & $P$ value \\
\hline Aortic valve implant size (mm) & & & & & $<.001$ \\
\hline Median & 25.0 & 23.0 & 25.0 & 27.0 & \\
\hline Q1, Q3 & $23.0,27.0$ & $23.0,25.0$ & $25.0,27.0$ & $25.0,27.0$ & \\
\hline Perfusion time (min) & & & & & $<.001$ \\
\hline Median & 108.0 & 82.0 & 135.0 & 170.0 & \\
\hline Q1, Q3 & $79.0,155.0$ & $66.0,112.0$ & $105.0,182.0$ & $127.0,208.0$ & \\
\hline Crossclamp time (min) & & & & & $<.001$ \\
\hline Median & 92.0 & 71.0 & 119.0 & 133.0 & \\
\hline Q1, Q3 & $67.0,128.0$ & $56.0,91.0$ & $94.0,138.0$ & $109.0,164.0$ & \\
\hline Circulatory arrest & $93(20)$ & $0(0)$ & $22(31)$ & $65(63)$ & $<.001$ \\
\hline CABG & $89(20)$ & $64(26)$ & $11(16)$ & $8(8)$ & $<.001$ \\
\hline Mitral valve surgery & $26(6)$ & $20(8)$ & $1(1)$ & $2(2)$ & .018 \\
\hline Tricuspid valve surgery & $9(2)$ & $9(4)$ & $0(0)$ & $0(0)$ & .039 \\
\hline Pulmonic valve surgery & $2(0)$ & $0(0)$ & $1(1)$ & $1(1)$ & .22 \\
\hline Other cardiac surgery & $247(54)$ & $39(16)$ & $70(100)$ & $103(100)$ & $<.001$ \\
\hline AF ablation surgery & $44(10)$ & $26(11)$ & $2(3)$ & $11(11)$ & .12 \\
\hline Other noncardiac surgery & $6(1)$ & $0(0)$ & $4(6)$ & $2(2)$ & .002 \\
\hline IABP inserted & $3(1)$ & $2(1)$ & $0(0)$ & $1(1)$ & .73 \\
\hline Postoperative blood products use & $191(42)$ & $98(40)$ & $30(43)$ & $44(43)$ & .85 \\
\hline Repeat sternotomy & $44(10)$ & $22(9)$ & $7(10)$ & $10(10)$ & .96 \\
\hline Reintubation & $16(4)$ & $6(2)$ & $3(4)$ & $6(6)$ & .29 \\
\hline Aortic valve surgery & & & & & $<.001$ \\
\hline Repair or reconstruction & $8(2)$ & $7(3)$ & $0(0)$ & $1(1)$ & \\
\hline Replacement only & $239(52)$ & $234(96)$ & $0(0)$ & $0(0)$ & \\
\hline $\begin{array}{l}\text { Replacement and separate insertion of } \\
\text { aortic conduit }\end{array}$ & $25(5)$ & $0(0)$ & $11(16)$ & $9(9)$ & \\
\hline Root reconstruction with valve conduit & $170(37)$ & $4(2)$ & $56(80)$ & $83(81)$ & \\
\hline Root reconstruction with valve sparing & $13(3)$ & $0(0)$ & $3(4)$ & $10(10)$ & \\
\hline Aortic valve implant type & & & & & $<.001$ \\
\hline Bioprosthesis & $418(92)$ & $235(96)$ & $64(91)$ & $85(83)$ & \\
\hline Homograft & $5(1)$ & $3(1)$ & $1(1)$ & $0(0)$ & \\
\hline Mechanical & $11(2)$ & $0(0)$ & $2(3)$ & $7(7)$ & \\
\hline None & $22(5)$ & $7(3)$ & $3(4)$ & $11(11)$ & \\
\hline Total ICU stay (h) & & & & & .65 \\
\hline Median & 28.3 & 28.1 & 30.2 & 26.7 & \\
\hline Q1, Q3 & $23.2,48.3$ & $23.5,46.7$ & $22.8,50.6$ & $22.7,48.4$ & \\
\hline Length of hospital stay (d) & & & & & .83 \\
\hline Median & 5.0 & 5.0 & 5.0 & 5.0 & \\
\hline Q1, Q3 & $4.0,6.0$ & $4.0,6.0$ & $4.0,6.0$ & $4.0,6.0$ & \\
\hline Readmitted to ICU & $21(5)$ & $15(6)$ & $2(3)$ & $2(2)$ & .18 \\
\hline Complications & $162(36)$ & $85(35)$ & $28(40)$ & $36(35)$ & .71 \\
\hline Reoperation for bleeding & $30(6.6)$ & $14(5.7)$ & $10(14.3)$ & $4(3.9)$ & .017 \\
\hline Perioperative MI & $1(0.2)$ & $0(0)$ & $1(1.4)$ & $0(0)$ & .08 \\
\hline Sternum deep infection & $0(0)$ & $0(0)$ & $0(0)$ & $0(0)$ & NA \\
\hline Postoperative stroke $>24 \mathrm{~h}$ & $3(0.7)$ & $0(0)$ & $0(0)$ & $1(1)$ & .22 \\
\hline TIA & $2(0.4)$ & $1(0.4)$ & $1(1)$ & $0(0)$ & .40 \\
\hline Prolonged ventilation $>24 \mathrm{~h}$ & $28(6)$ & $11(4)$ & $6(8.6)$ & $6(5.8)$ & .41 \\
\hline Pulmonary embolism & $2(0.4)$ & $1(0.4)$ & $0(0)$ & $1(1)$ & .64 \\
\hline Pneumonia & $11(2.4)$ & $9(3.7)$ & $0(0)$ & $2(1.9)$ & .21 \\
\hline Renal failure & $16(3.5)$ & $10(4)$ & $2(2.9)$ & $4(3.9)$ & .89 \\
\hline Permanent pacemaker & $17(4)$ & $11(4)$ & $2(2.9)$ & $4(3.9)$ & .83 \\
\hline
\end{tabular}




\begin{tabular}{|c|c|c|c|c|c|}
\hline \multirow[b]{2}{*}{ Variable } & \multirow[b]{2}{*}{$\begin{array}{c}\text { Entire cohort } \\
(n=456)\end{array}$} & \multicolumn{4}{|c|}{ Subgroups } \\
\hline & & $\begin{array}{c}\text { AVR AD }<45 \mathrm{~mm} \\
(\mathrm{n}=\mathbf{2 4 5})\end{array}$ & $\begin{array}{c}\text { AVR/AN } \\
\text { AD 45-49 mm }(n=70) \\
\end{array}$ & $\begin{array}{c}\text { AVR/AN AD } \geq 50 \mathbf{~ m m} \\
(\mathbf{n}=\mathbf{1 0 3})\end{array}$ & $P$ value \\
\hline Cardiac arrest & $7(1.5)$ & $4(1.6)$ & $1(1)$ & $1(1)$ & .89 \\
\hline Postoperative AF & $93(20)$ & $50(20)$ & $17(24)$ & $19(18)$ & .64 \\
\hline Readmission within $30 \mathrm{~d}$ & $55(12)$ & $27(11)$ & $8(12)$ & $16(16)$ & .48 \\
\hline Discharge mortality & $5(1.1)$ & $2(0.8)$ & $1(1.4)$ & $2(1.9)$ & .67 \\
\hline 30-d Mortality & $4(0.9)$ & $2(0.8)$ & $0(0)$ & $2(1.9)$ & .41 \\
\hline Operative mortality & $5(1.1)$ & $2(0.8)$ & $1(1.4)$ & $2(1.9)$ & .67 \\
\hline All-cause medium-term mortality & $37(8.1)$ & $24(9.8)$ & $2(2.9)$ & $9(8.7)$ & .18 \\
\hline
\end{tabular}

Data presented as n (\%), unless otherwise noted. $A V R$, Aortic valve replacement; $A D$, aortic diameter; $A N$, aneurysm; $A V R / A N$, AVR with ascending aortic replacement; $Q$, quartile; $C A B G$, coronary artery bypass grafting; $A F$, atrial fibrillation; $I A B P$, intra-aortic balloon pump; $I C U$, intensive care unit; $M I$, myocardial infarction; $T I A$, transient ischemic attack; $N A$, not applicable.

BAV and aortic dilatation of 45 to $49 \mathrm{~mm}$ can be performed safely without increasing the short- or medium-term morbidity or mortality. Aortic replacement to eliminate the threat of future dissection in patients with BAV can be accomplished with only an increase in pulmonary complications in those with larger ANs $(\geq 50 \mathrm{~mm})$. The decision to systematically commit to prophylactic aortic replacement in patients with BAV is complex. The 2006 ACC/ AHA guidelines were based on expert opinion and multiple reports of adverse outcomes in patients with BAV and untreated aortic dilatation $>45 \mathrm{~mm}$. Most recently, the 2013 Society of Thoracic Surgeons clinical practice guidelines have also reflected these concerns. ${ }^{10}$ They have concurred with the 2006 ACC/AHA guidelines by recommending that patients with genetically associated aortic disease (eg, BAV) should undergo aortic replacement when the AD has exceeded $50 \mathrm{~mm}$ and have taken the aggressive stance that aortic repair is indicated for all cardiac surgery patients

TABLE 3. Propensity score-matched analyses: pairwise comparisons of perioperative and postoperative outcomes among the 3 subgroups of interest

\begin{tabular}{|c|c|c|c|c|c|c|c|c|c|}
\hline \multirow[b]{2}{*}{ Variable } & \multicolumn{3}{|c|}{ PS-matched analysis 1} & \multicolumn{3}{|c|}{ PS-matched analysis 2} & \multicolumn{3}{|c|}{ PS-matched analysis 3} \\
\hline & $\begin{array}{c}\text { AVR } \\
\text { AD }<45 \mathrm{~mm} \\
(\mathrm{n}=\mathbf{4 7})\end{array}$ & $\begin{array}{c}\text { AVR/AN } \\
\text { AD } 45-49 \text { mm } \\
(n=47)\end{array}$ & $\begin{array}{c}P \\
\text { value }\end{array}$ & $\begin{array}{c}\text { AVR } \\
\text { AD }<45 \mathrm{~mm} \\
(\mathrm{n}=62)\end{array}$ & $\begin{array}{c}\text { AVR/AN } \\
\text { AD } \geq 50 \mathrm{~mm} \\
(\mathrm{n}=62)\end{array}$ & $\begin{array}{c}P \\
\text { value }\end{array}$ & $\begin{array}{c}\text { AVR/AN } \\
\text { AD } 45-49 \text { mm } \\
(\mathrm{n}=36)\end{array}$ & $\begin{array}{c}\text { AVR/AN } \\
\text { AD } \geq 50 \mathbf{~ m m} \\
(\mathbf{n}=\mathbf{3 6})\end{array}$ & $\begin{array}{c}P \\
\text { value }\end{array}$ \\
\hline Perfusion time (min) & & & $<.001$ & & & $<.001$ & & & .05 \\
\hline Median & 79 & 133 & & 84 & 146 & & 135 & 171 & \\
\hline Q1, Q3 & 65,124 & 105,171 & & 69,120 & 118,191 & & 111,174 & 134,198 & \\
\hline Crossclamp time (min) & & & $<.001$ & & & $<.001$ & & & .05 \\
\hline Median & 70 & 116 & & 72 & 126 & & 119 & 130 & \\
\hline Q1, Q3 & 56,97 & 94,135 & & 57,97 & 98,148 & & 99,137 & 114,152 & \\
\hline Reintubation & $0(0)$ & $2(4.3)$ & .15 & $0(0)$ & $6(9.7)$ & .012 & $0(0)$ & $4(11)$ & .040 \\
\hline Circulatory arrest & $0(0)$ & $14(30)$ & $<.001$ & $0(0)$ & $40(65)$ & $<.001$ & $12(33)$ & $27(75)$ & $<.001$ \\
\hline Complications & $16(34)$ & $21(45)$ & .29 & $18(29)$ & $25(40)$ & .19 & $13(36)$ & $15(42)$ & .63 \\
\hline Reoperation for bleeding & $3(6.4)$ & $7(15)$ & .18 & $3(4.8)$ & $4(6.5)$ & .70 & $3(8.3)$ & $3(8.3)$ & 1.00 \\
\hline Perioperative MI & $0(0)$ & $1(2.1)$ & .31 & $0(0)$ & $0(0)$ & NA & $0(0)$ & $0(0)$ & NA \\
\hline Postoperative stroke $>24 \mathrm{~h}$ & $0(0)$ & $0(0)$ & NA & $0(0)$ & $1(2)$ & .32 & $0(0)$ & $0(0)$ & NA \\
\hline TIA & $1(2.1)$ & $1(2.1)$ & 1.00 & $0(0)$ & $0(0)$ & NA & $0(0)$ & $0(0)$ & NA \\
\hline Ventilation $>24 \mathrm{~h}$ & $2(4.2)$ & $5(11)$ & .24 & $0(0)$ & $5(8)$ & .022 & $3(8.3)$ & $2(5.6)$ & .64 \\
\hline Pulmonary embolism & $1(2.1)$ & $0(0)$ & .31 & $0(0)$ & $1(1.6)$ & .32 & $0(0)$ & $0(0)$ & NA \\
\hline Pneumonia & $1(2.1)$ & $0(0)$ & .31 & $2(3.2)$ & $2(3.2)$ & 1.00 & $0(0)$ & $1(2.8)$ & .31 \\
\hline Renal failure & $3(6.4)$ & $2(4.3)$ & .65 & $1(1.6)$ & $4(6.5)$ & .17 & $0(0)$ & $2(5.6)$ & .15 \\
\hline Permanent pacemaker & $1(2.1)$ & $2(4.3)$ & .56 & $1(1.6)$ & $2(3.2)$ & .56 & $0(0)$ & $2(5.6)$ & .15 \\
\hline Cardiac arrest & $0(0)$ & $1(2.1)$ & .31 & $0(0)$ & $1(1.6)$ & .32 & $0(0)$ & $1(2.8)$ & .31 \\
\hline Readmission within $30 \mathrm{~d}$ & $6(13)$ & $6(13)$ & .97 & $11(18)$ & $8(13)$ & .48 & $4(11)$ & $5(14)$ & .69 \\
\hline Discharge mortality & $0(0)$ & $1(2.1)$ & .31 & $0(0)$ & $2(3.2)$ & .15 & $0(0)$ & $1(2.8)$ & .31 \\
\hline 30-d Mortality & $0(0)$ & $0(0)$ & NA & $0(0)$ & $2(3.2)$ & .15 & $0(0)$ & $1(2.8)$ & .31 \\
\hline All-cause midterm mortality & $2(4.3)$ & $2(4.3)$ & 1.00 & $5(8.1)$ & $7(11.3)$ & .54 & $1(2.8)$ & $3(8.3)$ & .30 \\
\hline
\end{tabular}

Data presented as n (\%), unless otherwise noted. $P S$, Propensity score; $A V R$, aortic valve replacement; $A D$, aortic diameter; $A N$, aneurysm; $A V R / A N$, AVR with ascending aortic replacement; $Q$, quartile; $M I$, myocardial infarction; $T I A$, transient ischemic attack; $N A$, not applicable. 
PS-Matched Analysis 1: AVR AD $<45 \mathrm{~mm}$ compared to AVR/AN AD $45-49 \mathrm{~mm}$

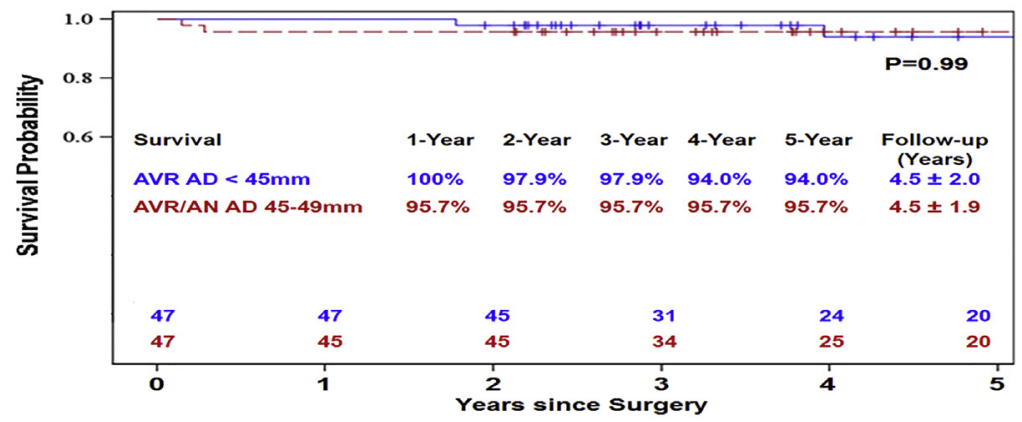

PS-Matched Analysis 2: AVR AD $<45 \mathrm{~mm}$ compared to AVR/AN AD $\geq 50 \mathrm{~mm}$

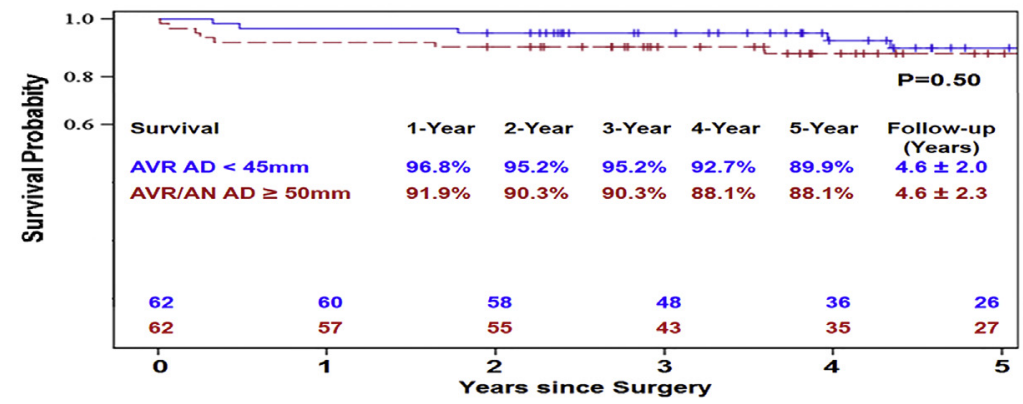

PS-Matched Analysis 3: AVR/AN AD $45-49 \mathrm{~mm}$ compared to AVR/AN AD $\geq 50 \mathrm{~mm}$

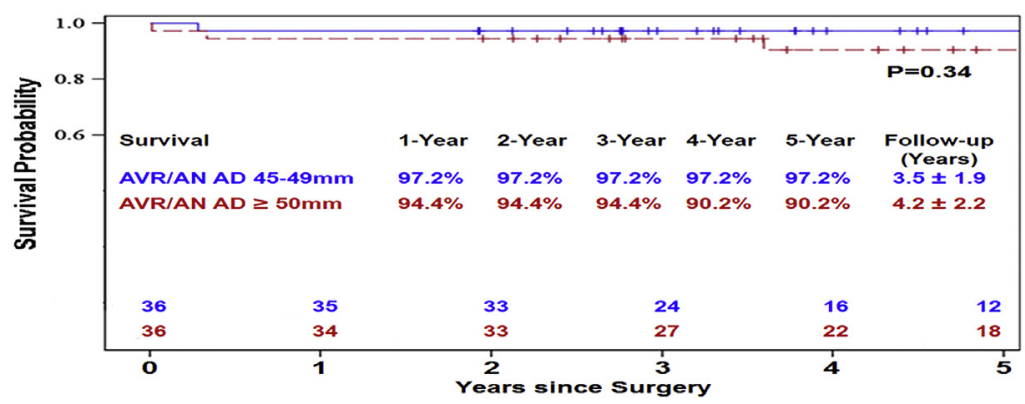

FIGURE 2. Propensity score (PS)-matched analyses with Kaplan-Meier overall survival curve estimates for pairwise comparisons among the 3 subgroups of interest (aortic valve replacement $[A V R]$ aortic diameter $[A D]<45 \mathrm{~mm}$, AVR/aneurysm $[A N]$ AD 45-49 mm and AVR/AN AD $\geq 50$ mm). Log-rank test-based $P$ values are reported for each 2-group comparison.

when the $\mathrm{AD}$ exceeds $45 \mathrm{~mm} .{ }^{10}$ Addressing the aorta at AVR for those with an AD of 45 to $49 \mathrm{~mm}$, however, adds to the complexity of the operation, which was shown by the longer crossclamp and cardiopulmonary bypass times and, sometimes, the use of circulatory arrest. However, this approach might avoid the complexity of a redo operation in patients who progress to aortic dilatation after AVR alone. Among our patients, no increase was seen in the incidence of perioperative myocardial infarction, stroke, hospital length of stay, 30-day hospital readmission, or 30day mortality in the AVR/AN group, with the exception of respiratory factors in those with an $\mathrm{AD}$ of $\geq 50 \mathrm{~mm}$. These findings provide further support toward continued compliance with contemporary guidelines. Circulatory arrest to facilitate hemiarch replacement was performed in 93 patients $(20 \%)$; however, it was mostly performed in those $(\mathrm{n}=65)$ with larger $(\geq 50 \mathrm{~mm})$ ANs with arch dilatation, of whom $63 \%$ had circulatory arrest. This decision was at the discretion of the surgeon on the basis of the distal ascending and arch diameters.

Previous studies of patients with BAV have suggested a threshold of $45 \mathrm{~mm}$ for consideration of concomitant aortic replacement at AVR. Svensson and colleageus ${ }^{11}$ reported findings from a less contemporary series of 1810 patients (1993-2003), with 20\% undergoing AVR/AN compared with $45 \%$ in our series. Most of their AVR cohort (95\%) 
had an aortic diameter $<46 \mathrm{~mm}$. They found no differences in 30-day mortality (1.2\% vs $1.1 \%$ in the AVR and AVR/ AN group, respectively) and similar freedom-from-late aortic events in each group ( $99 \%$ for AVR vs $97 \%$ in AVR/AN at 10 years). The investigators concluded that aortic dilatation $>45 \mathrm{~mm}$ should be considered a criterion for aortic replacement, because no additional short-term risk was found, with favorable long-term survival. ${ }^{11}$ Our results were similar to those from the Cleveland Clinic study but more contemporary. Also, our series included $91 \%$ of patients with BAV who had undergone preoperative CT or MRI, unique in published studies. These 2 factors likely account for the $45 \%$ AN resection in our group compared with $20 \%$ in the Cleveland series. Furthermore, we analyzed not just PS-matched AVR and AVR/AN groups but also the 3 subgroups.

Fedak and colleagues ${ }^{12}$ and Borger and colleagues ${ }^{13}$ have reported that patients with $\mathrm{BAV}$ and aortic root measurements of 45 to $50 \mathrm{~mm}$ undergoing isolated AVR have significantly greater risk of aortic ANs, dissections, and sudden death during follow-up. Russo and colleagues ${ }^{14}$ examined a series of 100 patients undergoing AVR (50 with BAV and 50 with a tricuspid aortic valve) and found significantly greater rates of acute aortic dissection and sudden death in the BAV group during nearly 20 years of follow-up. They recommended aggressive aortic replacement in patients with $\mathrm{BAV}$ and $\mathrm{AD}>40 \mathrm{~mm}$ during concomitant $\mathrm{AV}$ surgery. ${ }^{14}$ A recent review by Hardikar and Marwick ${ }^{15}$ combined the results of 32 studies and included 9441 patients with BAV, with $90 \%$ complete follow-up at an average of 7.7 years. They divided them into 3 groups: (1) those who did not undergo any operative intervention, (2) those who underwent AVR only, and (3) those who underwent any intervention on the aorta. ${ }^{15}$ They reported an annual mortality in the unoperated, AVR, and aortic surgery groups of $0.56 \% \pm 0.22 \%, 2.4 \% \pm 0.4 \%, 0.16 \% \pm 0.08 \%$, respectively. ${ }^{15}$ Additionally, they reported corresponding annual rates of acute aortic events, defined as the need for reintervention on the proximal aorta, aortic dissection or rupture, or sudden death not attributable to another cause, by group, of $0.29 \% \pm 0.03 \%, 0.68 \% \pm 0.13 \%$, and $0.16 \% \pm$ $0.08 \% .{ }^{15}$ Our study was unique in that we performed a detailed analysis of the data from a contemporary series of patients to examine the effect of compliance with the current ACC/AHA guidelines. Despite excellent review reports ${ }^{16}$ and expert commentary, a detailed analysis of the shortand medium-term outcomes when complying with the present guidelines has not been reported.

In contrast to these cited studies, controversy exists because others have suggested that an aortic root dimension of $45 \mathrm{~mm}$ in BAV might not be an appropriate criterion for prophylactic replacement. In a series of 252 patients with BAV who underwent surgery and were subsequently followed up for 9 years, Goland and colleagues ${ }^{17}$ identified a moderately dilated aorta $(45-49 \mathrm{~mm})$ in only $15.5 \%$ of patients, much lower than the $45 \%$ in our series. Aortic dilatation was not independently associated with increased mortality risk, and no significant differences in cardiac death were found between the AVR patients without aortic dilatation and those with AD of 45 to $49 \mathrm{~mm}$. Similarly, Girdauskas and colleagues ${ }^{18}$ recently reported on their 15-year follow-up in a series of patients with aortic stenosis and associated dilatation of 40 to $50 \mathrm{~mm}$, of whom $153(47 \%)$ had BAV. Only $3 \%$ of those with BAV and a dilated aorta in their cohort underwent repeat surgery during the duration of follow-up with no cases of aortic dissection. ${ }^{18}$ In addition, Michelena and colleagues ${ }^{19,20}$ recently reported a 20-year follow-up of 416 patients in Olmsted County Minnesota and reported excellent survival, with no aortic dissections, in patients with BAV and close clinical follow-up and no significant aortic stenosis or insufficiency. However, in our surgical series, the vast majority had aortic stenosis or aortic regurgitation, or both (Table 1).

A critique by Guntheroth ${ }^{21}$ on the present ACC/AHA guidelines suggested that in patients with $\mathrm{BAV}$ undergoing AVR, the risk of dissection might not outweigh the additional surgical mortality and morbidity associated with prophylactic aortic replacement. Given the low $(3 \%)$ rate of dissection attributed to BAV in the International Registry of Acute Aortic Dissection, ${ }^{22}$ the short- and long-term mortality ( $4 \%$ and $10 \%$, respectively) of aortic replacement was considered unacceptable. In a rebuttal, Bonow ${ }^{23}$ pointed out that previous studies had documented a 5 to 10 times greater risk of dissection in patients with BAV compared with that of the general population and that BAV was found in $13.6 \%$ of all acute dissections. These differing results from single-center studies have ranged from a benign long-term course (1 reoperation for aortic AN in a subgroup of 252 patients with BAV) ${ }^{17}$ to a markedly unfavorable postoperative course (8 late aortic events and 7 sudden deaths in the subgroup of 50 patients with BAV). ${ }^{14}$ Ultimately, for prophylactic aortic replacement to be routinely performed in patients with an $\mathrm{AD}$ of 45 to 49 $\mathrm{mm}$, the morbidity and mortality rate must be especially low, such as it was in our study ( $0.9 \%$ mortality). Hughes and colleagues ${ }^{24}$ recently reported greater mortality in hospitals performing $<30$ to 40 aortic procedures annually. A recent study using the Nationwide Inpatient Sample from the Healthcare Cost and Utilization Project revealed a substantial increase in the proportion of concomitant aortic procedures in patients with BAV undergoing AVR from 1998-1999 compared to $2008-2009(12.8 \%$ to $28.5 \%){ }^{25}$ Their data revealed no difference in mortality between the AVR and AVR/AN patients ( $1.5 \%$ vs $1.8 \%$; odds ratio, $1.02 ; 95 \%$ CI, 0.67-1.57). ${ }^{25}$

The precise etiology for aortic dilatation in patients with BAV disease remains unclear. The widespread belief that $\mathrm{BAV}$ disease is a congenital disorder of vascular connective 
tissue has played a role in the more aggressive prophylactic treatment recommendations of the proximal aorta in this patient population ${ }^{14,17}$ and is a philosophy that we have adopted. Although aortic dissection and rupture remain the most serious concerns with failure to proceed with complete resection of tissue at risk of molecular degeneration, it is likely that any sudden event would be preceded by progressive dilatation that would be diagnosed during follow-up or when symptoms arise. The complexity of a redo operation to replace the aortic root in a patient who has undergone an AVR is considerable, and, given the low morbidity and mortality of aggressive resection at AVR reported in our study, is likely an unnecessary risk.

Current guidelines are limited in that they fail to address a specific operative approach for individual patients with BAV aortopathy. It is now well recognized that BAV aortopathy is heterogeneous, ${ }^{26}$ and different patterns of aortic dilatation might relate to the location of cusp fusion. Accordingly, guidelines based on grouped data might be too conservative or too aggressive with respect to aortic replacement in this patient population. The use of 4dimensional MRI to map strain in the aorta might be capable of guiding surgeons toward individualized resection strategies; however, additional validation is needed before guidelines can be established. In the absence of such guidance, most patients in our series underwent a Bentall procedure with a bioprosthetic valve conduit to completely remove any tissue at risk of degeneration secondary to the underlying mechanisms suspected in BAV disease. Our outcomes using the Bentall procedure in this cohort of patients with BAV was $0.6 \% 30$-day mortality and $94.2 \% 3$-year overall survival. Some might criticize our approach as too aggressive, because other published studies have reported a mortality range of $3.6 \%$ to as great as $11 \% .{ }^{27-30}$ However, we think complete resection of the pathologic features is ideal and, as our results have demonstrated, will not increase mortality. A few of the AVR/AN cohort $(11.6 \%)$ underwent valve replacement with a separate aortic graft at the discretion of the surgeon, leaving the native supracoronary aortic tissue. A few received valve-sparing aortic root replacement. We found no differences in short- or medium-term mortality between these techniques.

Most of the complications reported in our study were respiratory in nature, specifically reintubation in patients with ANs $>50 \mathrm{~mm}$. These patients were also significantly more likely to undergo circulatory arrest, which likely contributed to their respiratory morbidity. Although our series of patients was not designed to investigate this, it is likely that the postoperative treatment of these complex patients should take into account this additional potential complication.

Because BAV is a relatively common congenital cardiac anomaly, future studies are needed to address the mechanisms of aortic aneurysm formation in this patient population and potential prophylactic interventions to prevent catastrophic events. Recent reviews have even suggested the existence of multiple phenotypes of BAV disease, leading to predominant stenosis or regurgitation, with the latter more likely to result in a persistent aortopathy more likely to result in aortic dissection. ${ }^{31}$ Retrospective analysis of existing imaging data with echocardiography, CT, and MRI have led Fazel and colleagues $^{32}$ to propose clustering patients with BAV into groups according to the anatomic patterns of aortic dilatation. They hypothesized that this novel categorization would lead to individualized recommendations for the extent of surgical intervention required. ${ }^{32}$ In addition, novel imaging methods such as multidetector $\mathrm{CT}^{33}$ and 4-dimensional $\mathrm{MRI}^{34}$ might improve risk stratification for those patients with BAV and aortopathy and predict the likelihood of progression and complications that might warrant earlier surgical intervention.

\section{Study Limitations}

Surgical decision making hinges on the ratio of risk to benefit. The present study focused only on the near-term risk of adding aneurysm surgery to patients with BAV. The long-term benefit of this approach must be derived from the published data because our compliance with the guidelines was so high. However, the exact risk of aortic complications in patients with BAV has been somewhat controversial. With our average patient age of 58 years, in our experience, untreated patients would face decades of risk from aortopathy complications.

Aortic dimensions were obtained by CT or magnetic resonance angiography in $91.4 \%$ of the entire cohort of 456 patients with BAV. The remainder had aortic dimensions obtained from echocardiography alone, which might have some inherent limitations for accurate aortic diameter measurements. However, previous studies of patients with BAV have primarily used aortic measurements obtained by echocardiography. ${ }^{11}$ The average follow-up of $4.7 \pm 2.1$ years in our study was shorter than that in other similar studies. Therefore, continued follow-up for adverse events is warranted in our patient population; however, our primary focus was on perioperative morbidity and mortality, which was comparable in the 2 groups. Late outcome data on death was determined from the Social Security Death Index, while other outcomes such as the incidence of aortic dissection might have been less complete. Although some concerns exist that PS matching will decrease the overall sample size, it must be emphasized that the AVR-only cohort was substantially older, with significant differences in multiple comorbidities, including, but not limited to, diabetes, heart failure, previous myocardial infarction, advanced New York Heart Association class (III and IV), and previous cardiac 
surgery or percutaneous coronary intervention. PS matching, therefore, was an effective method to eliminate such imbalances, and hence reduce the potential confounding, at the expense of sample size.

\section{CONCLUSIONS}

We have shown that in patients with BAV, we had 98\% compliance with the 2006 ACC/AHA recommendations for prophylactic aortic replacement in those with an $\mathrm{AD}$ of $\geq 45 \mathrm{~mm}$ at surgery. We found similar short- and medium-term mortality outcomes compared with AVR alone. This approach could prevent future aortic aneurysm complications and is, therefore, justified in centers with similar perioperative outcomes.

This work would not have been possible without the assistance of the support staff in the Division of Cardiac Surgery at Northwestern University and the Bluhm Cardiovascular Institute, including Jane Kruse, Colleen Clennon, and Linda Huerta.

\section{References}

1. Tzemos N, Therrien J, Yip J, Thanassoulis G, Tremblay S, Jamorski MT, et al. Outcomes in adults with bicuspid aortic valves. JAMA. 2008;300:1317-25.

2. Tadros TM, Klein MD, Shapira OM. Ascending aortic dilatation associated with bicuspid aortic valve: pathophysiology, molecular biology, and clinical implications. Circulation. 2009;119:880-90.

3. Edwards WD, Leaf DS, Edwards JE. Dissecting aortic aneurysm associated with congenital bicuspid aortic valve. Circulation. 1978;57:1022-5.

4. Roberts CS, Roberts WC. Dissection of the aorta associated with congenital malformation of the aortic valve. J Am Coll Cardiol. 1991;17:712-6.

5. Larson EW, Edwards WD. Risk factors for aortic dissection: a necropsy study of 161 cases. Am J Cardiol. 1984;53:849-55.

6. Bonow RO, Carabello BA, Kanu C, de Leon AC Jr, Faxon DP, Freed MD, et al. ACC/AHA 2006 guidelines for the management of patients with valvular heart disease: a report of the American College of Cardiology/American Heart Association task force on practice guidelines (Writing Committee to revise the 1998 guidelines for the management of patients with valvular heart disease): developed in collaboration with the Society of Cardiovascular Anesthesiologists, endorsed by the Society for Cardiovascular Angiography and Interventions and the Society of Thoracic Surgeons. Circulation. 2006; 114:e84-231.

7. Bonow RO, Carabello B, de Leon AC, Edmunds LH Jr, Fedderly BJ, Freed MD, et al. ACC/AHA guidelines for the management of patients with valvular heart disease: a report of the American College of Cardiology/American Heart Association Task Force on Practice Guidelines (committee on management of patients with valvular heart disease). J Am Coll Cardiol. 1998;32:1486-582.

8. Little RJ, Rubin DB. Causal effects in clinical and epidemiological studies via potential outcomes: concepts and analytical approaches. Ann Rev Pub Health. 2000;21:121-45.

9. Lin D. Goodness-of-fit tests and robust statistical inference for the Cox proportional hazards model. J Am Stat Assoc. 1989;84:1074-8.

10. Svensson LG, Adams DH, Bonow RO, Kouchoukos NT, Miller DC, O’Gara PT, et al. Aortic valve and ascending aorta guidelines for management and quality measures: executive summary. Ann Thorac Surg. 2013;95:1491-505.

11. Svensson LG, Kim KH, Blackstone EH, Rajeswaran J, Gillinov AM, Mihaljevic T, et al. Bicuspid aortic valve surgery with proactive ascending aorta repair. J Thorac Cardiovasc Surg. 2011;142:622-9.

12. Fedak PW, Verma S, David TE, Leask RL, Weisel RD, Butany J. Clinical and pathophysiological implications of a bicuspid aortic valve. Circulation. 2002; 106:900-4.
13. Borger MA, Preston M, Ivanov J, Fedak PW, Davierwala P, Armstrong S, et al. Should the ascending aorta be replaced more frequently in patients with bicuspid aortic valve disease? J Thorac Cardiovasc Surg. 2004;128:677-83.

14. Russo CF, Mazzetti S, Garatti A, Ribera E, Milazzo A, Bruschi G, et al. Aortic complications after bicuspid aortic valve replacement: long-term results. Ann Thorac Surg. 2002;74:S1773-6; discussion S1792-S1799.

15. Hardikar AA, Marwick TH. Surgical thresholds for bicuspid aortic valve associated aortopathy. J Am Coll Cardiol Img. 2013;6:1311-20.

16. Etz CD, Misfeld M, Borger MA, Luehr M, Strotdrees E, Mohr FW. Current in dications for surgical repair in patients with bicuspid aortic valve and ascending aortic ectasia. Cardiol Res Pract. 2012;2012:313879.

17. Goland S, Czer LS, De Robertis MA, Mirocha J, Kass RM, Fontana GP, et al. Risk factors associated with reoperation and mortality in 252 patients after aortic valve replacement for congenitally bicuspid aortic valve disease. Ann Thorac Surg. 2007;83:931-7.

18. Girdauskas E, Disha K, Borger MA, Kuntze T. Long-term prognosis of ascending aortic aneurysm after aortic valve replacement for bicuspid versus tricuspid aortic valve stenosis. J Thorac Cardiovasc Surg. 2014;1:276-82.

19. Michelena HI, Desjardins VA, Avierinos JF, Russo A, Nkomo VT, Sundt TM, et al. Natural history of asymptomatic patients with normally functioning or minimally dysfunctional bicuspid aortic valve in the community. Circulation. 2008; 117:2776-84

20. Michelena HI, Khanna AD, Mahoney D, Margaryan E, Topilsky Y, Suri RM, et al. Incidence of aortic complications in patients with bicuspid aortic valves. JAMA. 2011;306:1104-12.

21. Guntheroth WG. A critical review of the American College of Cardiology/American Heart Association practice guidelines on bicuspid aortic valve with dilated ascending aorta. Am J Card. 2008;102:107-10.

22. Coady MA, Stockwell PH, Robich MP, Poppas A, Sellke FW. Should aortas in patients with bicuspid aortic valve really be resected at an earlier stage than tricuspid? CON. Cardiol Clin. 2010;28:299-314.

23. Bonow RO. Bicuspid aortic valves and dilated aortas: a critical review of the ACC/ AHA practice guidelines recommendations. Am J Cardiol. 2008;102:111-4.

24. Hughes GC, Zhao Y, Rankin JS, Scarborough JE, O'Brien S, Bavaria JE, et al Effects of institutional volumes on operative outcomes for aortic root replacement in North America. J Thorac Cardiovasc Surg. 2013;145:166-70.

25. Opotowsky AR, Perlstein T, Landzberg MJ, Colan SD, O'Gara PT, Body SC et al. A shifting approach to management of the thoracic aorta in bicuspid aortic valve. J Thorac Cardiovasc Surg. 2013;146:339-46.

26. Fedak PW. Bicuspid aortic valve syndrome: heterogeneous but predictable? Eur Heart J. 2008;29:432-3.

27. Williams JB, Peterson ED, Zhao Y, O'Brien SM, Andersen ND, Miller DC, et al. Contemporary results for proximal aortic replacement in North America. J Am Coll Cardiol. 2012;60:1156-62.

28. Verbakel KM, van Straten AH, Hamad MA, Tan ES, ter Woorst JF. Results of one-hundred and seventy patients after elective Bentall operation. Asian Cardiovasc Thorac Ann. 2012;20:418-25.

29. Kalkat MS, Edwards MB, Taylor KM, Bonser RS. Composite aortic valve graft replacement: mortality outcomes in a national registry. Circulation. 2007;116: I301-6.

30. Etz CD, Homann TM, Rane N, Bodian CA, Di Luozzo G, Plestis KA, et al. Aortic root reconstruction with a bioprosthetic valved conduit: a consecutive series of 275 procedures. J Thorac Cardiovasc Surg. 2007;133:1455-63.

31. Girdauskas E, Disha K, Borger MA, Kuntze T. Risk of proximal dissection in patients with bicuspid aortic valve: how to address this controversy? Interact Cardiovasc Thorac Surg. 2014;18:355-9.

32. Fazel SS, Mallidi HR, Lee RS, Sheehan MP, Liang D, Fleischman D, et al. The aortopathy of bicuspid aortic valve disease has distinctive patterns and usually involves the transverse aortic arch. J Thorac Cardiovasc Surg. 2008;135:901-7.

33. Kang JW, Song HG, Yang DH, Baek S, Kim DH, Song JM, et al. Association between bicuspid aortic valve phenotype and patterns of valvular dysfunction and bicuspid aortopathy: comprehensive evaluation using MDCT and echocardiography. J Am Cardiol Img. 2013;6:150-61.

34. Mahadevia R, Barker AJ, Schnell S, Entezari P, Kansal P, Fedak PW, et al. Bicuspid aortic cusp fusion morphology alters aortic 3D outflow patterns, wall shear stress and expression of aortopathy. Circulation. 2014;129:673-82. 